\section{Birlesik Dünya Arastrma Cypriot Journal of Educational \\ Sciences}

Volume 15, Issue 3, (2020) 502-510

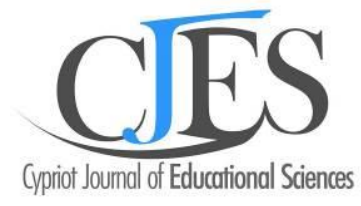

$\underline{\text { www.cjes.eu }}$

\title{
The effect of self- questioning strategy in developing independent thinking in teaching physics
}

Monther Bsharh Al-Swelmyeen a *, Associate Professor, Department of Basic Sciences, Princess Raham University College, Al-Balqa Applied University, Al Salt, Jordan. https://orcid.org/0000-0002-5163-2193

Mohammad Abed Sakarneh ${ }^{b}$, Associate Professor, Department of Special Education, Princess Raham University College, Al-Balqa Applied University, Al Salt, Jordan. https://orcid.org/0000-0001-8683-7941

Ghadeer Pernec Al zaben ' , Department of Sociology Delinquency and Criminology, Princess Raham University College, Al-Balqa Applied University, Al Salt, Jordan. ORCID: 0000_0003_2846_7799

\section{Suggested Citation:}

Monther Bsharh Al-Swelmyeen, Mohammad Abed Sakarneh \& Ghadeer Pernec Al zaben (2020). The Effectiveness of Self- Questioning Strategy in Developing Independent Thinking in teaching Physics. Cypriot Journal of Educational Science. 15(3), 502 - 510. DOI: 10.18844/cjes.v\%vi\%i.4918

Received from October 29, 2019; revised from January 5,2020; accepted from June 15, 2020. C2020 Birlesik Dunya Yenilik Arastirma ve Yayincilik Merkezi. All rights reserved..

\begin{abstract}
This study aimed at determining the effectiveness of self- questioning strategy in developing independent thinking in teaching physics. The researcher used the Independent Thinking Test on a purposive sample consisted of (46) students from the first secondary scientific class in Amman schools in Jordan. A quasi-experimental approach was adopted. To analyze the data a statistical Package for the Social Sciences (SPSS) was used. The study showed a statistically significant difference between the means of the two groups (experiment and control group) in the independent thinking level and it was in favor of the experimental group. The study recommended preparing and developing teaching programs according to the selfquestioning strategy and conducting similar studies on new samples at different age levels and new variables.
\end{abstract}

Keywords: Self-Questioning, independent Thinking, Physics.

* Monther Bsharh Al-Swelmyeen, Associate Professor, Department of Basic Sciences, Princess Raham University College, AlBalqa Applied University, Amman, Jordan.

E-mail address: $\underline{\text { dr.montherswelm@bau.edu.jo }}$ 


\section{Introduction}

Educators have sought to develop plans and programs that are in line with the world's scientific and technological development because the most important goals of the learning process are to develop the thinking of the learner, teach him research and discovery skills to enable him to deal successfully with the rapid developments and changes that result in different challenges in all aspects of life. One of the serious challenges in the educational systems is that the information provided to students are ready from its sources, whether this source is the teacher or the curriculum, which reduces the effectiveness of science and knowledge in the reality of the learner life (Hyassat, 2016; Sakarneh, 2014). However, the school is still seen as a place for transferring knowledge to students, while it should be a place for the enhancement of productive thinking in which students present their ideas through the practice of research, reasoning, perception, and other thought processes, as it is known that students reflect what they learn in their schools and apply it to their daily situations.

Thinking is considered one of the most important means of achieving conformity in an individual daily life, a series of mental processes and activities that the brain performs as a response to a stimulator that is received by one or more senses (Jarwan, 2010). Cognitive researchers define thinking as a mental process that is wisely developed through the individual's interaction and experience, aims to develop his cognitive structures, and to come up with new assumptions and expectations. This usually does not happen unless a problem is preceded by a hurdle that needs a solution (Abu Zainah \& Ababneh, 2007). Therefore, the thinking process includes number of thoughts, pictures, memories, and impressions lingering in the mind, which is received by sensory memory to be interpreted and given meaning through the long-term memory coding process (Abu Jado \& Nofal, 2010).

One of the significant strategies for developing thinking is the self- questioning strategy, as it is considered an effective and appropriate strategy that helps an individual to develop his thinking and to be positive when accessing, organizing, following up and evaluating information (Al-Hashemi \& Adulaimi, 2008; Sakarneh, \& Al-Swelmyeen, 2020). Also, it increases the individual's ability to apply the gained information in various learning and teaching situations. The self- questioning strategy, which is stemmed from the metacognitive strategies, is based on enabling the learner to ask himself a set of questions, so he becomes more integrated, and more aware of the process of productive and effective thinking, because the learning process relies mainly on the learner while the teacher is an engineer for the classroom environment, whose role is to direct and guides the learners during the learning process (Al-Hashemi \& Adulaimi, 2008).

Witkin, Oltman, Raskin \& Karp pointed out that, as indicated in Ashknani (2013), there are two styles of thinking which are: field-dependence, and field-independence. These styles are related to the individual's ability to isolate the studied topic, and to realize it within the surrounding field. That is, dealing with the individual's ability to analytic perception. The individual who is thinking independently can perceive parts of the field independently from its organized background. While the individual who is relying on the cognitive field of thinking realizes the field comprehensively (holistic) organization and his awareness of the parts of the field are vague. They also define independent thinking as the person's awareness of the situation in a way that is free from the domination of the field and he realizes things independently of that field. 
An independent thinking pattern develops simultaneously with growth. Hence, the learner becomes more self-reliant and freer to make decisions, an independent minded person, more confident and more mature in psychological terms. He actively deals with the environment, can use the logic widely, more aware of his own experiences and tends to analyze things highly. In addition to being motivated, clear specific objectives, and tends to solve problems without direct instructions. While the person in the dependent field works routinely, negative, has a less sense of security, psychologically immature, and his feelings are less consistent (Hammad, 2011; Sakarneh, Paterson \& Minichiello, 2016.)

It has become necessary to apply effective teaching methods and techniques, considering the different thinking patterns among students. One of these effective teaching methods and strategies is self- questioning strategy. This strategy is one of the metacognitive strategies that require the activation of mental processes by the learner before, during, and after reading. Its importance stems from its ability to shift the learning of the student from quantitative learning to qualitative learning that aims to make him the focus of the educational process, through the mental development of the learner, and the development of his thinking in an exciting educational environment, in which tools and means are available, and increase the student's ability to think in the tasks he performed (AlHashemi and Adulaimi, 2008). Recently, the studies dealing with the importance of the selfquestioning strategy and its effect on science education have increased. A study conducted by AlBahadeli (2012) showed the impact of using the self-questioning strategy in development of inductive and deductive thinking skills in achieving the knowledge structure of science. Also, Khaji (2014) pointed to the effectiveness of using the self-questioning strategy in achieving and recalling physics among fourth-grade students.

Several studies have addressed the subject of the strategy of self-questioning. A review was conducted. Daniel and Williams (2019) reviewed the influence of self-questioning (SQ) strategy instruction; they found that there were no direct effects of such strategy on improving students' outcomes for students with special needs. Al-Qahtani and Al-Qasim (2018) conducted a study aimed at determining the effectiveness of teaching science using the question of self-questioning in academic achievement and the development of contemplative thinking skills. The study showed that there were statistically significant differences in achievement and contemplative thinking skills for the benefit of students of the experimental group who studied science according to the self-questioning strategy. Asfour (2016) also conducted a study aimed at determining the effectiveness of employing a selfquestioning strategy to develop systemic thinking skills in the life sciences subject for eleventh grade students. The study showed that there were statistically significant differences between the mean scores of the two study groups in the systemic thinking test in favor of students of the experimental group who studied according to the questioning strategy. Al-Dahdouh (2015) conducted a study aimed to identify the effect of employing a self-questioning strategy in developing a solution to the physical issue compared to a peer learning strategy among students of the eleventh scientific class in Gaza in Palestine. The study results showed that there were no statistically significant differences in the development of the solution to the physical problem due to the teaching strategy (self-questioning and peer learning). Ashknani (2013) also conducted a study aimed at determining the relationship between metacognitive and dependent/ independent thinking among university students in the light of the variables of the student's gender, specialization, and academic level. The study showed that there were statistically significant differences between independent thinking and adopted thinking in the degree of correlation of thinking behind memory with approved thinking and independent thinking, in favor of independent thinking. Anderson (2012) also conducted a study aimed at determining the impact of the self-questioning strategy on acquiring some research skills during the 
research project for physics at the University of Montana, USA. The study showed a positive effect of the self-questioning strategy on students' acquisition of research skills.

It is clear from previous studies that there is no study that dealt with the relationship between the strategy of self-questioning and independent thinking in particular, despite the fact that the strategy of self-questioning has been the subject of many studies, and independent thinking as well. The researchers have benefited from previous studies in developing the study problem and preparing the tool which is a measure including some sections, and in checking the reliability and validity of the measure. The researchers also benefited from the results of previous studies in comparing and contrasting them with the results of this study considering that the results of previous studies have dealt with various variables, such as: gender, specialization, academic level, or academic achievement. As for this study, it addresses the strategy of self-questioning and determining its effectiveness in independent thinking, and this gave it a distinction from previous studies. Within the limits of the researchers' knowledge there was no previous study that addressed the effect of the self-questioning strategy in developing independent thinking in the Jordanian secondary school context. The problem of this research is limited to the effect of using self- questioning strategy in developing independence thinking in teaching physics among the secondary stage students in Jordan. The study problem is demonstrated in the following research question:

- Are there statistically significant differences at the level of significance $(\alpha=0.05)$ in the level of independent thinking of secondary school students due to the teaching method (self-question, and traditional)?

\section{Methodology}

\subsection{Research Methodology}

The researchers adopted the quasi-experimental approach to determine the effectiveness of the self-questioning strategy in the level of independent thinking, and in a manner that is appropriate for the study's objectives and answering its questions.

\subsection{Research Population}

The study was applied to a purposive sample of (46) students in the first secondary scientific grade in Al-Ittifaq Schools under the Education of the University District in Amman, Jordan. Then they were randomly divided into two groups, the experimental and control groups with (23) students in each group.

\subsection{Research Tools}

1. The Group Embedded Figures Test:

It was pre and post applied to the experimental, and control groups, and it is a standardized test that was rebuilt by Al-Sharqawi in 1977 to suit the Egyptian context, then it was standardized by Elian and Hassan, referred to in (Al-khawaldeh, 2006), at the Measurement Center at the University of Jordan to suit the Jordanian context. It is considered one of the quick tests that are performed at a specific time, and it measures the degree of field awareness among a group of individuals at the same time. The Group Embedded Figures Test include three separate sections: 
A. The first section: consists of (7) items designed to train the student on how to respond to the test, and the time allocated to answer this section is two minutes. The grades of the student are not counted for this section.

B. The second and third sections: Each section comprises of nine items, the time allocated to respond to them is five minutes each, and the total number of items is considered to be the examiner 's total grade on the test. Items in the three sections include a complex geometric shape that includes a simple shape inside it. The student is required to define the simple shape using the pen, and the inability of the examiner to see the simple shape and the complex shape surrounding it at one time was considered when designing the test. The simple forms required to be identified were placed on the last page of the test, and the test included examples of how to respond.

The time allocated to the whole test is (30 minutes) including the section where the researchers explain the instructions of the test and how to respond to each question. Respondents must adhere to the allocated time for each section because the test is one of the speed tests, the allocated period for each of the sections is as follows: The first section: two minutes, the second section: five minutes, and the third section five minutes. These steps are followed in applying the test tool:

1. Students fill out their details on the first page.

2. The examiner reads the test instructions, as well as clarifying the two resolved problems, reminding that it is necessary to mark all lines, and erase the incorrect lines.

3. When all students have finished reading the instructions and examples, the examiner gives a starting signal, an opportunity for questions, assistance and clarification are provided to the students. A time of two minutes is only allocated to perform on the first section, and during that the students are guided to make sure they understand the method of responding, as this section is for training only, and after two minutes the work on this part ends whether the student has completed it or not.

4. Students move to the second section, which is made up of nine questions that they answer with a specific time of five minutes, with reminding them to work as quickly as possible and stop after the lapse of five minutes, without moving to the third part.

5. The same work is repeated in the third section, considering the time allocated for the answer, which is five minutes.

\subsection{Test Correction}

The student's responses are considered correct for the items if he identifies all the borders of the simple shape included in the complex shape, but if he cannot identify all the dimensions of the shape. His answer is considered incorrect, as well as if he selects another shape that is not required then the answer is also incorrect. The student is given one mark for each valid item, and its marks are collected in the second and third sections only. No mark is counted from the first section as it is for training only. It is necessary to check the student's answers to the items of this section to ensure that he has understood the instructions and mastered the method of responding. Thus, the highest mark obtained by the student is (18) and the higher the student's degree, the more an indication of his independence from the cognitive field.

\subsection{Validity and Reliability of the Test}

Hassan and Elian referred to in (Al-khawaldeh, 2006) obtain the concurrent validity, by applying the scale to (235) male and female students from the secondary and university levels. They calculated the correlation coefficient between the students' scores on the scale and their scores on a criterion test 
(which also measures the degree of the domain). The correlation coefficient value of the concurrent validity was $(-0.50)$ and the minus sign of the correlation coefficient indicate the opposite of the meaning of the large sign on the two scales to the degree of perception. So, its increase on (GEFT) means high independence in the degree of cognition, while its increase on the criterion test means weak independence in the cognitive degree. This degree of validity is sufficient. The reliability of the tool was determined by calculating the half-correlation coefficient between the marks of the second and third sections of the members of the validity sample and it was (0.76). Correcting this split half reliability coefficient by the Spearman-Brown equation and the corrected value was (0.86).

In this study, the scale was applied twice to an exploratory sample consisted of (30) male and female from outside the study sample, in which the characteristics of the main sample were represented, with a two-week time difference. The coefficient reliability was $(0.81)$ and this value was considered acceptable for this study.

\section{The Scientific Subject}

The scientific subject included a chapter on "operation and energy" in the physics book to be taught to first secondary school students- Scientific section- in Jordanian schools. The material was prepared according to the self-question strategy. It was presented to a group of arbitrators who are specialize in methods of teaching science, teachers, and educational supervisors of physics. Their comments and suggestions were taken into consideration. The material was taught to students of the experimental group while the students of the control group were taught according to the traditional method.

\subsection{Research Procedures}

To achieve the research objectives the following steps and procedures were followed:

- Reviewing the educational literature related to the field of the current research and studies related to the subject of the study.

- Preparing the study tool in its final form and verifying its psychometric properties.

- Determining the total study population and selecting the study sample based on the random method.

- Applying the study tools to the sample members in their classrooms, explaining the instruction for answering the study tool.

- Applying the measurement tool to the members of the study sample and then collecting statistical data and extracting results using the SPSS and finally discussing the results and writing recommendations.

\subsection{Statistical Analyzes}

To answer the study question, the statistical program (SPSS) was used by calculating the arithmetic mean and the standard deviations for the scores of the members of the study sample in the pre and post applications then using the analysis (ANCOVA).

\subsection{Research Variables}

1. The independent variables which are the method of teaching and have two levels: - self-questioning - traditional

2. The dependent variables: the level of independent thinking. 


\section{Discussion of Results}

To answer the research question, which states the following: Are there statistically significant differences at the level of significance $(\alpha=0.05)$ in the level of independent thinking of high school students due to the teaching method (self-question, traditional)?. Arithmetic means and standard deviations were calculated for the responses of (experimental group and control group) during the pre and post applications of the GEFT to the experimental and control groups as shown in Table (1).

Table 1. Mean and SD for the responses of the (experimental and control) during the pre and post application to GEFT on the experimental and control groups

\begin{tabular}{lllll}
\hline Application & Group & No. & Mean & SD \\
\hline Pre- & Experimental & 23 & 10.7391 & 3.15101 \\
& Control & 3 & 9.5217 & 2.82633 \\
& Overall & 6 & 10.1304 & 2.98867 \\
Post & Experimental & 23 & 13.7391 & 1.73775 \\
& Control & 3 & 9.7391 & 2.75049 \\
& Overall & 6 & 11.7391 & 2.24412 \\
\hline
\end{tabular}

Table (1) shows that there are apparent differences between the averages of the performance of the members of the two experimental study groups in the post-application to group embedded figures test due to the teaching method (self-questioning strategy, the traditional method). The mean of student responses in the experimental group was (13.7391) while the mean of students' performance in the control group was (9.7391). The analysis of (ANCOVA) was applied to neutralize the differences in the pre-test and this is shown in Table (2).

Table (2): Analysis of Covariance (ANCOVA) Between the Two Groups (The Experimental and the Control) Groups on the Embedded Figures Test

\begin{tabular}{llllll}
\hline Variance Source & SS & DF & MS & P Value & Sig \\
\hline ANCOVA & $184.000 a$ & 1 & 184.000 & $34.766^{*}$ & .000 \\
Method & 184.000 & 1 & 184.000 & $34.766^{*}$ & .000 \\
Error & 232.870 & 44 & 5.292 & & \\
Total & 416.870 & 46 & & & \\
& & & & &
\end{tabular}

Table (2) shows the presence of statistically significant differences at the level of significance $(\alpha=$ 0.05 ) in the students' responses on the (GEFT) that due to the teaching method (self-questioning strategy, the traditional method) after the differences were controlled on the pre-test, the value ( $P$ ) according to the ANCOVA was (34.766), which is statistically significant as the level of significance $(.0000)$ is less than the specified level $(\alpha=0.05)$. This means that there are statistically significant 
differences at the level ( $\alpha=0.05$ ) in students' responses on the (GEFT) attributed to the teaching method (self-questioning strategy, traditional method) in favor of the experimental group who was taught using the self-questioning strategy. As indicated in Table (1) the mean of the grades of the members of the experimental group who studied physics according to the question of self-question on the test (GEFT) is (13.7391) which is higher than the mean of the grade of the control group who was studied by using the traditional way which is (9.7391). This indicates that the differences were in favor of students of the experimental group who studied according to the self-questioning strategy.

The researchers interpret this result by the fact that the experimental group students who studied according to the self-questioning strategy have better performance than the control group students who studied through the traditional way because self-questioning strategy is an active cognitive process that focuses on the positive aspects of the learner and his activity. The information is not provided directly but the students are directed to obtain them in a functional framework. In addition to the diversity and continuity of activities where the learner plans, implements, and collects evidence about needed knowledge. This result can also be attributed to the fact that teaching according to the self-questioning strategy allows the learner to practice most of the scientific thinking skills such as: observation, prediction, measurement, reasoning, experimentation, and imposing and testing hypotheses, which helps students acquire thinking skills independently. Teaching through a selfquestioning strategy can contribute to correcting wrong information, if any, in their cognitive context, learning from error, deepening their understanding of the scientific subject and assimilating it, achieving self-learning with them, leading themselves, and achieving significant progress in the learning structure ( Al-Bahadeli, 2012). Also, training students to raise questions increases the assimilation of the scientific subject, concentration, reach new predictions, define the most important information, and develop thinking skills.

According to the researchers, this finding came because of the nature of self-questioning strategy which draws the attention of the students and raises their interest in the subject of the lesson and makes the lesson more inspiring which encourage them to constantly raise various questions and consequently achieving the transformation of the learning effect in an easy way as well as the application of knowledge which is the most important objectives and requirements of teaching physics in particular. Although there was no related literature addressed the effect of the selfquestioning strategy in developing independent thinking, but the results of previous studies have shown the effectiveness of the self-questioning strategy on the variables that they addressed. AlQahtani and Al-Qassim, 2018 and Hafez, 2015 indicated the superiority of this strategy in the field of increasing achievement among learners. The studies of (Asfour, 2016; Al-Dahdouh, 2015) also indicated the effectiveness of this strategy in providing students with problem-solving skills and thinking skills in its various forms.

\section{Conclusion}

This study aimed at determining the effectiveness of self- questioning strategy in developing independent thinking in teaching physics. From the results, it can be concluded that the selfquestioning strategy increases the ability of students to plan and organize their learning independently and autonomously so that they can make plans for learning activities that include determining the learning requirements.

\section{Recommendations}

The study recommended preparing and developing teaching programs according to the selfquestioning strategy and conducting similar studies on new samples at different age levels and new variables. 


\section{References}

Abu Jado, S., Nofal, M. (2010). Teaching Thinking. Dar Almasira, Amman, Jordan.

Abu Zainah, F., Ababneh, A. (2007). Mathematics Curricula for the First Three Grades. 2nd ed, Dar Almasira, Amman, Jordan.

Al-Bahadeli, M. (2012). The effect of adopting science teachers for both the questioning strategy and direct teaching by integrating the skills of inductive and deductive thinking in achieving the components of knowledge building for the science subject and developing contemplative thinking skills among students. Journal of Educational Studies, 5 (19), 59-106.

Al-Dahdouh, A. (2015). The effect of employing the question of self-question in developing the skills of solving the physical problem compared to the peer learning strategy of students of the eleventh grade - Gaza. Master Thesis, Alazhar University, Gaza, Palestine.

Al-Hashemi, A., Adulaimi, T. (2008). A Modern Teaching Strategy. 1st ed, Dar Alshoroq for publishing \& distribution, Amman, Jordan.

Al-khawaldeh, A. (2006). The effectiveness of a computerized educational software according to the systems approach in acquiring scientific concepts and developing scientific thinking skills among students of the basic stage who have a dependent / independent cognitive style from the field. (Unpublished dissertation), Amman Arab University, Amman- Jordan.

Al-Qahtani, H., Al-Qasim, M. (2018). The Effectiveness of Teaching Science Using the Self-Questioning Strategy in Academic Achievement and Developing Contemplative Thinking Skills. Journal of Educational and Psychological Studies. Sultan Qaboos University, Sultanate of Oman, 13 (1), 151-174.

Al-Sharqawi, A. (2003). Contemporary Cognitive Psychology. Anglo Egyptian Bookshop, Cairo.

Anderson, J. (2012). Effects of Questioning Strategies on Students Inquiry Skills During A Physics Research Project. (Unpublished master thesis), science education, Montana state university, U.S.A.

Asfour, A. (2016). The effectiveness of employing a self-questioning strategy to develop systemic thinking skills in the biology subject for eleventh grade students in gaza governorates. (Unpublished thesis), Alazhar University, Gaza.

Ashknani, F. (2013). The relationship between metacognitive and dependent / independent thinking among university students considering some variables. (Unpublished Master thesis), Amman Arab University, Amman, Jordan.

Daniel, J., Williams, K. (2019). Self-Questioning Strategy for Struggling Readers: A Synthesis. Retrieved Jun 21, 2020, from https://journals.sagepub.com/doi/10.1177/0741932519880338\#.

Hammad, S. (2011). the effect of a training program based on the two theory of the theory of bikropropr and zinski on developing knowledge independence and achieving information identity among adolescents in jordanian society. (Unpublished Dissertation), University of Jordan, Amman- Jordan.

Hyassat, M. (2016). The Voice of Jordanian Parents of Young Children with Disabilities on Involvement in Their Children's Educational Services. International Journal of Special Education. 31 (3).

Jarwan, F. (2010). Teaching Thinking. Dar Alfikr: Publishers and distributors, Amman.

Khaji, Th. (2014). The Effectiveness of The Self- Questioning Strategy in Obtaining and Recalling Fourth-Grade Students in Physics. Al-Fatih journal, 10 (57), 124-155.

Sakarneh, M. (2014). Jordanian Education Reform between the Ideal and the Actual. Developing Country Studies, 4 (20), 65-73.

Sakarneh, M. A., Al-Swelmyeen, M. B. (2020). The Extent to Which the Jordanian Inclusive Basic School Teachers Use the Constructivism Theory in Teaching. Journal of Educational and Social Research, 10 (1), 182-197. https://doi.org/10.36941/jesr-2020-0017

Sakarneh, M., Paterson, D. \& Minichiello, V. (2016). The Applicability of the NSW Quality Teaching Model to the Jordanian Primary School Context. Dirasat Journal: Educational Sciences, 43 (4 Supplement), 1773-1789.

Witkin, A., Oltman, K, Raskin, E. \&Karp, A. (1971). Group Embedded Figures Test Sampler Set (Manual and Sample Figures and Scoring). Mind Garden, Inc, www.mindgarden.com, Retrieved 2, February 2018. 